\title{
DOSSIE
}

\section{Relações étnico-raciais e integração curricular no ensino das Ciências Humanas ${ }^{1}$}

\author{
Ethnic-racial relations and curricular integration \\ in Human Sciences teaching
}

\author{
Guilherme Babo Sedlacek \\ Doutorando em História na USP \\ Professor do IFSC - Campus Xanxerê \\ guilherme.babo@ifsc.edu.br \\ Rodolfo Denk Neto \\ Doutor em Filosofia Política pela UFSC \\ Professor do IFSC - Campus Xanxerê \\ rodolfo.denk@ifsc.edu.br
}

\begin{abstract}
RESUMO: O artigo apresenta um trabalho sobre a educação das relações étnico-raciais, temática obrigatória desde a promulgação das leis que incluíram nos currículos escolares a História e Cultura AfroBrasileira e Indígena, campo privilegiado de estudos na área das Ciências Humanas. Abordam-se estas questões a partir de uma experiência com esta temática na produção de material didático nesta área para cursos de ensino médio técnico. A concepção de currículo integrado desses cursos permite trabalhar numa perspectiva transversal, visando a uma educação antirracista. Apresentam-se duas abordagens, uma histórica, acerca do racismo e o escravismo, e outra filosófica, ligada aos direitos humanos, ambas no contexto regional do Oeste catarinense. Pretende-se mostrar que o trabalho transversal é um meio eficaz de investigar as relações étnico-raciais através da interseccionalidade, contribuindo para a consolidação de uma prática de pesquisa e de ensino significativa e que revele mais da realidade local em que se vive e se ensina.
\end{abstract}

PALAVRAS-CHAVE: Cursos Técnicos Integrados ao Ensino Médio. História e Cultura Afro-brasileira e Indígena. Direitos Humanos.

\footnotetext{
ABSTRACT: This paper presents a working experience with the ethnic-racial relations education, which is a mandatory subject in the Afro-Brazilian and Indigenous History and Culture school curricula. It reports the experience with the theme through a didactic material preparation for technical high school courses. These courses integrated curriculum conception enables one to work in a transversal perspective, aiming at an antiracist education. It presents two approaches, a historical one, regarding racism and

${ }^{1}$ A pesquisa que originou este trabalho foi patrocinada pela Pró-Reitoria de Pesquisa, Pós-Graduação e Inovação (PROPPI) e pela Diretoria de Assuntos Estudantis (DAE) do Instituto Federal de Santa Catarina.
} 
Revista do Corpo Discente do Programa de Pós-Graduação em História da UnB

EM TEMPO DE HISTóRIAS | Brasília-DF | n. 36 | p. 252-272 | jan./jun. 2020.

ISSN 2316-1191

slavery, and a philosophical one, concerning the human rights, both within the West of Santa Catarina regional context. It intends to demonstrate that the transversal work is an effective way of researching the ethnic-racial relations through intersectionality, contributing to a meaningful research and teaching practice that better shows the living and teaching local reality.

KEYWORDS: Technical Courses Integrated to High School. Afro-Brazilian and Indigenous History and Culture. Human Rights.

Educação para as relações étnico-raciais é um dos assuntos que mais têm interessado gestores, professores e pesquisadores dedicados ao ensino em níveis fundamental e médio no Brasil no século XXI. Demanda social colocada pelos movimentos negros e indígenas, materializada na legislação educacional através das leis $\mathrm{n}^{\circ} 10.639 / 2003$ e $\mathrm{n}^{\circ} 11.645 / 2008$, a educação das relações étnico-raciais se apresenta como um tema privilegiado para a área das Ciências Humanas. Pretendemos aqui compartilhar uma experiência de trabalho com esta temática no planejamento curricular, pesquisa multidisciplinar e elaboração de material didático realizada pelos professores de Ciências Humanas no Câmpus Xanxerê do Instituto Federal de Santa Catarina (IFSC). O trabalho foi desenvolvido a partir de uma perspectiva que se propôs a relacionar as abordagens das relações étnico-raciais e a temática dos direitos humanos por meio de uma investigação a respeito da diáspora africana e da imigração haitiana no Oeste catarinense.

Este trabalho se deu articulado com a construção de um currículo integrado para os cursos técnicos do câmpus, e traz como contribuições mais expressivas a iniciação científica a partir de um tema transversal e o desenvolvimento de pesquisas sobre as relações étnico-raciais contextualizadas à realidade regional do Oeste catarinense. Acreditamos que as reflexões sobre esta experiência prática podem ser de grande interesse para a construção curricular de gestores e professores, sobretudo, aqueles atuantes em outros câmpus de institutos federais de educação do país e em escolas aderentes ao Novo Ensino Médio.

\section{Integração curricular em Ciências Humanas}

Embora não seja de modo algum uma novidade, o currículo integrado ainda pode ser considerado uma tendência inovadora em relação aos padrões educacionais predominantes no país. Uma vez que vislumbra à formação para o trabalho como um "princípio educativo" que também prepare o estudante para a inserção no mercado, a integração curricular foi um modelo privilegiado para a organização do ensino técnico na expansão da Rede Federal de Educação Profissional, Científica e Tecnológica, desde 2008. Recentemente, com a Reforma do Ensino Médio (Lei ${ }^{\circ} 13.415 / 2017$ ), houve a reestruturação curricular contemplando a Base Nacional Comum Curricular (BNCC) e a adoção de um dos cinco itinerários formativos possíveis, dentre os quais a formação técnica e profissional. Assim, a integração curricular desenvolvida nas instituições federais de educação profissional e tecnológica proporciona um grande e diversificado conjunto de experiências que podem contribuir para as escolas das redes públicas de ensino que adotem o Novo Ensino Médio, com formação geral e formação técnica 
Revista do Corpo Discente do Programa de Pós-Graduação em História da UnB

Em TEMPO DE HISTóRIAS | Brasília-DF | n. 36 | p. 252-272 | jan./jun. 2020.

ISSN 2316-1191

voltadas para a atuação cidadã e a atividade laboral, objetivando uma educação emancipatória.

Alguns entraves ainda se colocam diante dos gestores e professores para que integração curricular possa ser efetivada, como a indisponibilidade de cargas horárias adequadas para o planejamento coletivo e a falta de uma formação para o trabalho integrado nos cursos de licenciatura, bem como de capacitação e formação continuada dos profissionais de educação. Adriano Larentes da Silva (2014, p. 16), destaca que a efetivação dessa integração tinha pela frente inúmeros desafios e disputas, como necessidade de realizar uma travessia complexa e contraditória, rompendo com a Pedagogia das Competências e apostando na formação dos educadores de modo a criar condições para mudanças na concepção curricular e prática pedagógica.

Também é importante destacar que há grandes possibilidades abertas aos docentes e gestores da Rede Federal que seria relevante que estivessem colocadas também para as escolas que adotarem o Novo Ensino Médio. O regime de dedicação exclusiva é predominante e permite que alguma parte da carga horária dos docentes seja destinada a elaboração e execução de projetos de ensino, pesquisa e extensão, o que amplia também as possibilidades para uma educação integral do estudante do Ensino Médio, através da iniciação extensionista e científica. Assim, a baixa carga horária disponível para a BNCC, em comparação ao Ensino Médio tradicional, poderia ser compensada através do protagonismo discente nos projetos e da indissociabilidade entre ensino, pesquisa e extensão.

No Câmpus Xanxerê, os docentes da área propedêutica precisam trabalhar com cargas horárias extremamente reduzidas, mesmo em comparação a outros câmpus mais antigos do IFSC. O mínimo necessário para reconhecimento dos cursos, de acordo com o Catálogo Nacional de Cursos Técnicos, foi adotado como máximo pela instituição para a aprovação dos Cursos Técnicos Integrados ao Ensino Médio do câmpus. Assim, há apenas 2.000 horas para as unidades curriculares da formação geral e 1.200 horas para a formação técnica. A Lei $n^{0}$ 13.415/2017 definiu um limite de 1.800 horas para a BNCC no Novo Ensino Médio e o restante para os itinerários formativos, sendo o mínimo total de 3.000 horas. Vemos que as cargas horárias se aproximam bastante entre o modelo do Câmpus Xanxerê e a realidade daqueles colégios que adotarem o Novo Ensino Médio com itinerário formativo de formação técnica e profissional.

Apesar das possibilidades abertas pelos projetos de ensino, pesquisa e extensão, não são todos os estudantes que têm a possibilidade ou o interesse em participar dos mesmos, de modo que os docentes do Câmpus Xanxerê ainda têm que efetuar escolhas na seleção de conteúdos e conhecimentos a serem trabalhados com os estudantes nas reduzidas cargas horárias das unidades curriculares. Para as Ciências Humanas, o total previsto nos projetos pedagógicos dos Cursos Técnicos Integrados ao Ensino Médio é de 440 horas, divididos da seguinte forma:

$1^{\circ}$ Ano: Filosofia - 40h, Geografia - 80h, História - 80h, Sociologia - 40h;

$2^{\circ}$ Ano: Filosofia - 40h, Geografia - 40h, História - 40h, Sociologia - 40h; e

$3^{\circ}$ Ano: Geografia - 20h, História - 20h. 
Revista do Corpo Discente do Programa de Pós-Graduação em História da UnB

Em TEMPO DE HISTóRIAS | Brasília-DF | n. 36 | p. 252-272 | jan./jun. 2020.

ISSN 2316-1191

Diante desse tempo exíguo, a integração curricular não poderia tomar um tempo a mais na organização curricular, necessitando ser encarada como solução. Além disso, se já há uma grande dificuldade para o trabalho com temáticas transversais no Ensino Médio regular, em acordo com os Parâmetros Curriculares Nacionais do Ensino Médio (PCN-EM), a integração da propedêutica com as áreas técnicas é ainda mais desafiadora. Daí que se optou por efetuar, primeiramente uma integração curricular das Ciências Humanas como primeiro passo, para depois realizar a integração com o restante da área propedêutica e as áreas técnicas.

Assim, a solução vislumbrada pelos docentes responsáveis pelo grupo de unidades curriculares relativas à área das Ciências Humanas (Filosofia, Geografia, História e Sociologia), quando foram elaborados os projetos pedagógicos dos cursos técnicos do Câmpus Xanxerê, foi otimizar o escasso tempo de aula, estruturando o currículo a partir de uma concepção de integração por temas. A ideia principal é que as discussões de conteúdos próximos ocorressem de forma sincrônica, para facilitar sua consolidação e a aprendizagem a partir de uma perspectiva transdisciplinar. Isso também evita a necessidade de revisões de conteúdos trabalhados por uma disciplina quando forem demandados para a outra, e permite que os docentes não percam tempo com repetições. Em segundo nível, as diferentes unidades buscaram a integração dos conteúdos e conhecimentos por conceitos que reforcem a interdisciplinaridade, ao mesmo tempo em que expressem as particularidades do conhecimento filosófico, geográfico, histórico e sociológico.

O primeiro ano dos cursos possui maior carga horária que os demais e o terceiro ano apenas permite um breve trabalho de fechamento e consolidação do percurso formativo em História e Geografia. Por isso, foram selecionados dois temas integradores para o primeiro ano, "Trabalho, tecnologia e cultura" e "Relações de Poder", um tema integrador para o segundo ano, "Desigualdade e diferença", e um tema integrador para o terceiro ano, "Ética e cidadania", este último trabalhado em Filosofia e Sociologia no segundo ano. A partir desses temas integradores, os docentes desenvolveram eixos temáticos para selecionar e organizar os conteúdos suas unidades curriculares em cada ano. Por fim, para cada disciplina foram definidos conceitos integradores que articulam os eixos temáticos ao longo dos três anos, tal como segue:

Filosofia: antropologia filosófica;

Geografia: produção do espaço geográfico;

História: temporalidades, rupturas e permanências; e

Sociologia: interações e transformações sociais.

Não se pretendeu com isso ignorar a concepção de ensino por competências, deduzidas das relações entre resultados e habilidades. O Exame Nacional do Ensino Médio (ENEM) configura seu desenho avaliativo próximo a essa proposta de orientação educacional do currículo por competências e constitui-se como importante exame de acesso de seleção, incentivo e ingresso para a continuação dos estudos em nível superior, aspecto que uma educação inclusiva não pode perder de vista. Apenas não se procurou evitar que a noção de competência (saber-fazer) fosse o modelo norteador do currículo, valorizando outras opções de itinerários formativos que estivessem em acordo com os 
Revista do Corpo Discente do Programa de Pós-Graduação em História da UnB

Em TEMPO DE HISTóRIAS | Brasília-DF | n. 36 | p. 252-272 | jan./jun. 2020.

ISSN 2316-1191

PCN-EM. Além da integração das áreas de conhecimento por competências, esse documento determina que o trabalho docente em todas as áreas deve contemplar seis temas transversais (Pluralidade cultural; Trabalho; Ética e Política; Cidadania e Direitos Humanos; Meio ambiente; Orientação sexual). Os temas integradores do grupo curricular das Ciências Humanas foram definidos a partir desses temas transversais, das especificidades desta área de conhecimento e das áreas técnicas dos cursos.

\section{Pesquisando as relações étnico-raciais e os direitos humanos como projeto de integração curricular}

Uma vez realizado o trabalho de planejamento de um currículo integrado, fez-se necessário dar início a pesquisas sobre os temas integradores e à elaboração de materiais de apoio didático para trabalhar este currículo. No âmbito de tema integrador "Trabalho, tecnologia e cultura" foram definidos os subtemas "relações étnico-raciais" e "educação especial" como primeira experiência para desenvolvimento das pesquisas e materiais didáticos transdisciplinares. A Lei $\mathrm{n}^{\circ}$ 10.639, de 9 de janeiro de 2003, e a Lei $\mathrm{n}^{0} 11.645$, de 10 de março de 2008, alteraram a Lei n 9.394/1996, ou Lei de Diretrizes e Bases da Educação Nacional (LDB), para incluir nos currículos a obrigatoriedade da temática "História e Cultura Afro-Brasileira e Indígena". Isso trouxe uma centralidade ao ensino das relações étnico-raciais, como uma espécie de novo tema transversal para a educação básica, o que poderia ser aproveitado como perspectiva principal para discutir as relações de trabalho, a produção tecnológica e a pluralidade cultural de forma crítica, desconstruindo preconceitos e evidenciando desigualdades sociais.

Recentemente, outra medida importante para a realidade da Rede Federal foi a assinatura, em 2016, do Pacto Nacional Universitário Pela Promoção do Respeito à Diversidade, da Cultura de Paz e dos Direitos Humanos. Assim, a educação em direitos humanos também teve que ser curricularizada nos cursos das instituições signatárias do pacto, como o IFSC. Uma temática transversal prevista pelos PCN-EM foi incorporada aos currículos de todos os cursos, desde aqueles de formação inicial até a pós-graduação.

Optou-se então por desenvolver um projeto de pesquisa aplicada ao ensino das relações étnico-raciais e dos direitos humanos, reunindo os quatro docentes de Ciências Humanas e quatro bolsistas. Os projetos de pesquisa foram aprovados nos editais internos do IFSC - PROPPI/DAE n 20/2017 e nº 34/2017 - "Pesquisa como princípio educativo", sendo desenvolvidos entre agosto de 2017 e julho de 2018. Dessa forma, o tema integrador "Trabalho, tecnologia e cultura" passou a ser pesquisado a partir dos subtemas "relações étnico-raciais" e "educação especial" de forma que a própria elaboração de materiais didáticos fosse realizada a partir de uma perspectiva interseccional. $\mathrm{O}$ trabalho se desdobrou em um material didático no qual propomos a reflexão sobre as relações étnico-raciais estudando a história do conceito de interseccionalidade, associado ao feminismo negro e ao conceito de lugar de fala. Seguindo a definição de Dayane Assis (2019, p. 18):

a) interseccionalidade é uma das ferramentas teórico-metodológicas possíveis para entender as múltiplas opressões; b) a interseccionalidade não estabelece 
Revista do Corpo Discente do Programa de Pós-Graduação em História da UnB

Em TEMPO DE HISTóRIAS | Brasília-DF | n. 36 | p. 252-272 | jan./jun. 2020.

ISSN 2316-1191

uma hierarquia ou somatória de opressões; c) o lugar de fala de cada indivíduo é multirreferenciado a partir de suas experiências.

Para além da interseccionalidade, também fomos orientados por uma concepção de pesquisa como princípio educativo. Segundo Demo (2006, p. 42-43):

\begin{abstract}
Pesquisa como princípio científico e educativo faz parte de todo processo emancipatório, no qual se constrói o sujeito histórico autossuficiente, crítico e autocrítico, participante e capaz de reagir contra a situação de objeto e de não cultivar o outro como objeto. Pesquisa como diálogo é processo cotidiano integrante do ritmo de vida, produto e motivo de interesses sociais em confronto, base da aprendizagem que não se restrinja à mera reprodução. $\mathrm{Na}$ acepção mais simples, pode significar conhecer, saber, informar-se para sobreviver, para enfrentar a vida de modo consciente.
\end{abstract}

Além disso, procurou-se desenvolver uma estética da sensibilidade que estimule a valorização da pluralidade cultural e o respeito às diferenças por meio do ensino da temática das relações étnico-raciais. Assim, a pesquisa enfocou as identidades e tradições culturais do Oeste catarinense e os perfis étnico e socioeconômico da população dos municípios da área de abrangência do câmpus, bem como um mapeamento das deficiências na região. Visou-se com isso a elaboração de estratégias de ensino e de materiais didáticos para a educação para as relações étnico-raciais de forma contextualizada às demandas e peculiaridades da comunidade regional.

Xanxerê está localizada no Oeste catarinense, região que concentra o maior número de aldeias indígenas no estado, com uma população aproximada de 10 mil indígenas, predominantemente das etnias kaingang e guarani. Apesar disso, as populações permanecem invisibilizadas nas políticas públicas e nota-se grande preconceito com estas culturas por parte dos não indígenas da região. Cabe ainda destacar que as relações étnico-raciais também perpassam as ações de inclusão de imigrantes haitianos e seus descendentes no Oeste catarinense, principal parcela da população negra da região.

Algumas iniciativas já haviam sido desenhadas no sentido da aproximação do câmpus a estas comunidades. O professor de História atuou como formador de professores kaingang e guarani na Ação Saberes Indígenas na Escola, coordenada pelo Museu de Arqueologia e Etnologia da Universidade Federal de Santa Catarina (MArqueE/UFSC). Isso o colocou em contato com professores e anciãos das aldeias do Oeste catarinense e permitiu o desenvolvimento de ações de extensão no Câmpus Xanxerê com a participação dos mesmos, tais como oficinas de alimentação tradicional kaingang para estudantes do Curso Técnico em Alimentos Integrado ao Ensino Médio e palestras com professores indígenas para os estudantes do câmpus. Os professores de Linguagens e de Ciências Humanas haviam também organizados um curso de Formação Inicial e Continuada (FIC) chamado "Língua Portuguesa e Cultura Brasileira para estrangeiros" para atender à demanda da Associação dos Haitianos de Xanxerê (AHXA). Isso permitiu aos professores uma troca com a comunidade de haitianos e conhecer melhor a realidade dos imigrantes, desconstruindo estereótipos reforçados pela mídia.

A experiência no trabalho com as comunidades indígena kaingang e guarani e de imigrantes haitianos trouxe para os professores e bolsistas envolvidos no projeto a oportunidade de pesquisar de maneira regionalmente contextualizada o ensino das 
Revista do Corpo Discente do Programa de Pós-Graduação em História da UnB

Em TEMPO DE HISTóRIAS | Brasília-DF | n. 36 | p. 252-272 | jan./jun. 2020.

ISSN 2316-1191

relações étnico-raciais a partir do tema integrador "Trabalho, tecnologia e cultura". Ocorreram reuniões formativas com os quatro professores da área de Humanas e as quatro bolsistas que tiveram por objetivo procurar pontos de convergência entre os debates das diferentes unidades curriculares, estruturar os planejamentos curriculares e seleção de conteúdos a serem trabalhados no $1^{\circ}$ ano dos Cursos Técnicos Integrados ao Ensino Médio e escolher estudos de caso que seriam utilizados no material didático multidisciplinar desenvolvido para o eixo temático. Assim, a pesquisa foi importante como princípio educativo para a formação das bolsistas e dos professores na área de Humanas de forma multidisciplinar, tendo realizado importantes avanços na reflexão teórica e na elaboração do perfil étnico e socioeconômico da região, bem como no mapeamento das deficiências.

Para a condução da pesquisa, cada um dos professores de Ciências Humanas determinou uma linha de pesquisa dentro do projeto, bem como objetivos específicos e metodologias adequadas a esta linha. O professor de História trabalhou com a "História e cultura afro-brasileira e indígena no Oeste Catarinense", objetivando pesquisar sobre a presença afro-brasileira e das culturas indígenas da região, desde o Império até o tempo presente. Foram para este fim utilizados os métodos de pesquisa em arquivos disponíveis online, a análise de periódicos do banco de dados da Hemeroteca Digital, o levantamento iconográfico e análise de história oral. Em Filosofia, investigaram-se os "Fundamentos filosóficos da criação e afirmação dos direitos humanos", visando ao desenvolvimento da capacidade de leitura crítica, de escrita, de sistematização e deliberação argumentativa sobre o percurso histórico e filosófico dos direitos humanos no Brasil e no mundo através de pesquisas sobre os fundamentos históricos e filosóficos das primeiras discussões e criações de legislações no viés dos direitos humanos no Brasil e no mundo, destacando-se que foi pesquisada a imigração de haitianos para Xanxerê. Buscou-se investigar como os haitianos compreendem os direitos humanos e se os mesmos foram respeitados na sua jornada, bem como compreender e verificar se os direitos foram e se são garantidos no Brasil.

Para os objetivos deste artigo, centraremos nossa discussão nas linhas de pesquisa mencionadas, que desenvolveram a temática da educação das relações étnicoraciais, das diásporas africanas e dos direitos humanos a partir de uma perspectiva interseccional. Os resultados compartilhados nas próximas seções correspondem aos conteúdos selecionados e conhecimentos construídos para a produção do material multidisciplinar e vêm sendo utilizados nos últimos anos para o ensino em Ciências Humanas.

\section{Educação das relações étnico-raciais no Brasil e no Oeste catarinense}

Uma vez realizado o planejamento curricular e realizada a pesquisa multidisciplinar, chegamos ao momento de elaboração do material didático numa perspectiva transversal. As primeiras questões que procuramos responder no sentido de introduzir a temática das relações étnico-raciais aos estudantes foram: "por que estudar a educação das relações étnico-raciais?" e "se não existem raças humanas, falar de relações raciais não seria racismo?”. As respostas a estas questões orientaram a redação 
Revista do Corpo Discente do Programa de Pós-Graduação em História da UnB

EM TEMPO DE HISTóRIAS | Brasília-DF | n. 36 | p. 252-272 | jan./jun. 2020.

ISSN 2316-1191

da introdução do material e convêm ser aqui compartilhadas como experiência que vem se demonstrando positiva.

Podemos dizer que o ensino de História do Brasil surge com a criação do Colégio Pedro II e do Instituto Histórico e Geográfico Brasileiro, no início do Segundo Reinado. Nesse momento, a diversidade ainda era vista como um problema a ser resolvido por um projeto de civilização e homogeneização, o que esteve relacionado à defesa da superioridade da raça branca sobre as demais. Segundo os representantes do Império, os indígenas deveriam ser incorporados, por uma assimilação branda (José Bonifácio de Andrada) ou uma assimilação violenta (Francisco Adolfo de Varnhagen) (ALMEIDA, 2010, p. 145-146). Analogamente, a assimilação dos africanos por meio do tráfico atlântico e da escravidão era justificada como uma "redenção espiritual dos negros", que sairiam da barbárie e do paganismo para a civilização e a cristandade.

$\mathrm{Na}$ Primeira República, visões opostas sobre a questão da miscigenação entram em disputa. Alguns autores destacaram a inautenticidade da cultura brasileira, manifestando um pessimismo social, como na ideia das "três raças tristes" (Eduardo Prado) ou na atribuição do atraso nacional à degeneração racial (Euclides da Cunha). Outras visões são marcadas pela valorização da mestiçagem como característica principal da cultura e do povo brasileiro (Mário de Andrade). A ênfase na ideia do convívio harmonioso das diferentes raças no país (Affonso Celso e Gilberto Freyre), deu origem ao "mito da democracia racial", que seria reforçado durante o Estado Novo, quando se buscou eliminar identidades regionais e elaborar uma síntese da nacionalidade do povo brasileiro enquanto uma "raça de mestiços" (BITTENCOURT, 2007).

Apesar de tantas ressignificações da temática da questão racial, sempre esteve presente a ideia de que a sociedade brasileira é caracterizada pela miscigenação, ou seja, pela mistura entre grupos étnicos. Tanto no final do Império, com o crítico literário Silvio Romero, quanto na Primeira República, como o diretor do Museu Nacional do Rio de Janeiro, João Batista Lacerda, vemos disseminada a ideia de que o Brasil é um "país mestiço" ou um "país miscigenado", em consonância com ideia que os estrangeiros partilhavam do Brasil (SCHWARCZ, 1994, p. 137-138). No entanto, isso não se traduz em igualdade de condição para toda a população. Em nosso país, ainda persiste a ideia étnico-racial que privilegia a brancura, valorizando a cultura europeia, e inferiorizando a cultura indígena, africana e asiática. Sendo assim, desenvolve-se uma incorporação de valores, historicamente construídos, que desqualifica atributos físicos, tradições culturais e valores de alguns grupos étnicos.

Considerando as diferenças entre brancos, negros e indígenas na sociedade, fruto de relações sociais historicamente constituídas, as políticas públicas têm o papel de objetivar a reparação, o reconhecimento e a valorização da identidade, cultura e história dos indígenas e negros brasileiros. Sendo assim, discutir as relações étnico-raciais que construíram o Brasil deveria ser uma obrigação de todos: sistemas de ensino, comunidade, professores, alunos e seus pais, não importando sua origem ou etnia.

Vale salientar que o conceito de raça, utilizado nos períodos colonial e imperial da história brasileira, era designado para classificar grupos étnicos conforme determinadas características, como cor de pele, aspecto físico, estatura. Tais 
Revista do Corpo Discente do Programa de Pós-Graduação em História da UnB

EM TEMPO DE HISTóRIAS | Brasília-DF | n. 36 | p. 252-272 | jan./jun. 2020.

ISSN 2316-1191

características eram associadas à origem social do indivíduo. Entendendo o negro como protagonista da sua própria história e potência de emancipação, o termo raça, originalmente carregado de preconceito, foi ressignificado pelo Movimento Negro e passou a ser utilizado com o propósito de valorizar o legado deixado pelos africanos. Sabemos hoje que não existem raças humanas, mas não se pode por esta razão negar ou omitir um histórico de relações étnico-raciais que se traduzem em desigualdades sociais e na persistência do racismo (SANTOS, 1984).

Para uma educação das relações étnico-raciais é importante esclarecer como ocorre o processo de construção e aceitação da identidade negra. Processo esse, marcado pela luta contra desvalorização constante da cultura africana e de seus aspectos físicos. Muitos questionamentos sempre são colocados aos professores que se propõem a discutir identidade negra em sala, o que torna a temática ainda mais relevante, embora também demande uma abordagem segura para a desconstrução de preconceitos. Afinal, negro é aquele que assim se identifica ou aquele que é visto como tal? Antes de mais nada, acreditamos que o professor deve reforçar que ser negro no Brasil trata-se de uma escolha política. Não se limita a características físicas, mas também, leva-se em conta a sua ancestralidade, sendo uma autodenominação identitária.

O mesmo raciocínio é válido para pensar a identidade indígena. O termo "índio" também foi inicialmente usado como referência a diversos povos que habitavam o continente americano. Suas culturas foram desqualificadas como "primitivas" a partir desse termo genérico que negava suas identidades étnicas. Hoje, muitas vezes o preconceito se manifesta em frases como: "são aculturados" ou "não tem cara de índio" (ARAPYUM; CRUZ, 2017).

Temos procurado reforçar no ensino das relações étnico-raciais, através do material didático multidisciplinar produzido na pesquisa, que culturas são dinâmicas e se modificam através de trocas e contatos com outros povos. Os descendentes de colonos europeus também modificaram suas culturas ao longo da nossa história e a troca de elementos culturais com os povos indígenas, enriqueceu ambas os lados. O Movimento Indígena também ressignificou um termo originalmente racista e passou a utilizá-lo para valorizar suas tradições culturais. Assim, autoidentificar-se como indígena é um direito e também uma atitude política. Como diz a pedagoga Iára Ferreira Arapyun (2017): "Ser indígena é um sentimento de pertencimento, não cabendo ao Estado ou a um não indígena dizer quem é ou não índio".

\section{Diáspora africana e racismo na América portuguesa e no Império do Brasil}

Ensinar a história das culturas afro-brasileiras e indígenas oferece aos professores uma perspectiva privilegiada para o desenvolver uma educação antirracista, abordando as relações étnico-raciais a partir de uma abordagem interseccional. A diáspora africana do período do escravismo colonial (séculos XV a XVIII) e do segundo escravismo (século XIX) apresenta pontos de interseção relevantes com a história de povos indígenas submetidos à escravização e outras formas de trabalhos compulsórios (LEWKOWICZ; GUTIÉRREZ; FLORENTINO, 2008). Não por acaso, esses povos foram chamados de "negros da terra", durante o período colonial. A partir de um enfoque de 
Revista do Corpo Discente do Programa de Pós-Graduação em História da UnB

EM TEMPO DE HISTóRIAS | Brasília-DF | n. 36 | p. 252-272 | jan./jun. 2020.

ISSN 2316-1191

gênero, percebemos que a violência contra a mulher negra também é maior em nossa sociedade como fruto do escravismo, de maneira que uma educação antirracista e uma educação antimachista, ou antimisógina têm sido trabalhadas pelo currículo integrado pelo tema das relações étnico-raciais.

Uma questão importante com relação à diáspora africana que vem sendo desconstruída pelos historiadores é a imagem que naturaliza africanos e indígenas como "escravos", o que impacta diretamente na nossa percepção crítica das relações étnicoraciais como historicamente construídas. Uma maneira importante de combatermos os preconceitos raciais no ensino e destacando que a escravidão foi imposta sempre a povos que nasciam em África ou nas Américas como livres e que, como consequência de guerras, tornavam-se "escravizados". Diversos documentos históricos nos ajudam a entender como se dava o processo de escravização de povos africanos e indígenas no século XIX, permitindo-nos desnaturalizar a noção de escravidão e ressaltar que todos os escravos indígenas, africanos, afrodescendentes ou mestiços no Brasil eram indivíduos que perderam sua liberdade por meio da violência ou que nasceram em cativeiros como descendentes de indivíduos originalmente livres.

A violência (simbólica e física) perpassa todas as dimensões da instituição da escravidão, deixando profundas marcas, principalmente, nas sociedades que tiveram seu sistema produtivo baseado no comércio e no trabalho de seres humanos escravizados. O trabalho com fontes históricas primárias e novas perspectivas historiográficas em sala de aula permite a aproximação do ensino de história à temática das relações étnico-raciais e a produção de novos conhecimentos escolares. No caso do material didático produzido na pesquisa, priorizou-se o estudo a partir da discussão sobre escravidão, apresentando tanto rupturas quanto continuidades entre o período da agroexportação escravista colonial das Américas (séculos XVI e XVIII) e o do segundo escravismo (ou segunda escravidão) que existiu no Brasil, em Cuba e nos EUA do século $\mathrm{XIX}^{2}$.

Como um dos estudos de caso, destacamos o transporte de africanos e indígenas escravizados, na África ou no Brasil. Geralmente, os traficantes e autoridades, nos períodos do tráfico legal ou ilegal, costumavam fazer o transporte de grupos de escravos por meio do chamado "libambo", que poderia ser uma corrente de ferro, troncos de madeira ou mesmo uma corda usada para amarrar diversas pessoas pelo pescoço e facilitar o transporte do grupo de prisioneiros. Temos testemunhos importantes retirados da historiografia para o ensino sobre história da escravidão, como o de um diula (comerciante muçulmano nativo) chamado Mungo Park, que atuou numa região da África Ocidental que corresponderia ao atual território da Gâmbia, no século XVIII, descrevendo como eram realizadas as operações para abastecimento dos mercados

\footnotetext{
2 Originalmente cunhado por Dale Tomich como second slavery, o termo tem sido traduzido por autores como João José Reis e Sidney Chalhoub como "segundo escravismo" e por autores como Rafael Marquese e Ricardo Salles como "segunda escravidão". Refere-se ao novo sistema econômico que levou à expansão do escravismo nas Américas de finais do século XVII e do século XIX, como consequência das transformações operadas pela Revolução Industrial e pelas independências nacionais americanas (CHALHOUB, 2012; MARQUESE; SALLES, 2016).
} 
Revista do Corpo Discente do Programa de Pós-Graduação em História da UnB

Em TEMPO DE HISTóRIAS | Brasília-DF | n. 36 | p. 252-272 | jan./jun. 2020.

ISSN 2316-1191

escravistas transatlântico e transaariano. Segundo Park, na sua caravana, os escravos eram transportados

colocando a perna direita de um e a esquerda de outro no mesmo par de grilhões. Sustentando-se os grilhões com uma corda, eles podem caminhar, embora muito lentamente. Cada quatro escravos estão da mesma maneira amarrados pelos pescoços, com uma forte corda de correias trançadas, e à noite, um par adicional de grilhões é colocado nas suas mãos, e algumas vezes uma leve corrente de ferro é passada em volta dos seus pescoços. (Apud LOVEJOY, 2002, p. 153).

Samuel Crowler, um iorubá escravizado, é outro que deixou seu testemunho sobre como esta prática ocorria em África no século XIX e permite aos estudantes ter contato com um testemunho africano sobre o transporte em libambo. Crowler destaca que, durante a batalha em que foi capturado, as mulheres e crianças tentaram escapar para dentro do matagal, mas acabaram aprisionadas também:

[...] enquanto elas estavam procurando se desvencilhar dos arbustos, foram alcançadas e capturadas pelos inimigos com uma laçada de corda jogada sobre o pescoço de cada uma, para serem conduzidas à maneira das cabras amarradas juntas, sob direção de um homem. Em muitos casos uma família era violentamente dividida entre três ou quatro inimigos, e cada um levado embora, para não se verem mais. Seu humilde servo foi assim capturado - com sua mãe, duas irmãs (uma delas uma criança de cerca de dez meses) e uma prima enquanto tentava escapar da maneira descrita acima. (Apud LOVEJOY, 2002, p. 223).

Embora o Oeste catarinense seja uma região que nem mesmo integrava o território da América portuguesa e só foi integrado ao Império do Brasil em meados do século XIX, essas práticas escravistas não deixam de ser interessante para o estudo da realidade regional. Durante o período das expedições bandeirantes do século XVII e das Guerras Guaraníticas (1753-1756), as populações indígenas da região foram submetidas a práticas similares de apresamento e escravização. É fato que durante o período do segundo escravismo a região não tinha nenhuma vila ou assentamento regular de não indígenas, apenas o aldeamento de Palmas, que pertencia à província do Paraná. Ainda assim, muitos autores têm chamado a atenção para a disseminação da escravização ilegal de indígenas após o fim do tráfico atlântico (ALMEIDA, 2009; CUNHA, 2012).

Essa realidade pode-se ver até mesmo quando se apresenta mascarada nos documentos oficiais, como o relatório do presidente da província do Paraná que informava ter recebido em Curitiba uma comitiva de índios kaingang de Palmas liderada pelo cacique Veri, que lhe solicitou, entre outras coisas, que desse "[...] ordem para ser-lhe entregue um filho, que se achava em casa de pessoa daquele município" (PARANÁ, 1854, p.60). A partir da temática das práticas de escravização é possível desnaturalizar as narrativas familiares, recorrente no Oeste catarinense, segundo as quais "minha avó era índia mesmo, foi pega no laço", destacando a violência contra os povos indígenas da região, em especial com relação às mulheres.

A violência da escravidão e do racismo deixam outras marcas que podem ser vistas, por exemplo, nas práticas policiais. A criminalização da afrodescendência e o tratamento dispensado aos negros no país foram registradas pelo fotógrafo do Jornal do Brasil, Luiz Morier, no Rio de Janeiro da década de 1980. Ao acompanhar uma batida policial numa favela da Zona Norte da cidade, Morier registrou a prática do "libambo" 


\section{Finstortorias}

Revista do Corpo Discente do Programa de Pós-Graduação em História da UnB EM TEMPO DE HISTóRIAS | Brasília-DF | n. 36 | p. 252-272 | jan./jun. 2020.

ISSN 2316-1191

ocorrendo nos anos finais da ditadura civil-militar brasileira. Posteriormente, comprovou-se que se tratavam apenas de trabalhadores, como o fato de alguns segurarem as carteiras de trabalho nas mãos já indicava nos registros fotográficos. $\mathrm{O}$ trabalho com a sequência de imagens registradas por Morier, dentre as quais a principal vemos reproduzida abaixo (imagem 1), permite um trabalho comparativo com outras imagens do libambo em África ou no Império, apresentando aos estudantes a persistência das práticas escravistas nas relações étnico-sociais.

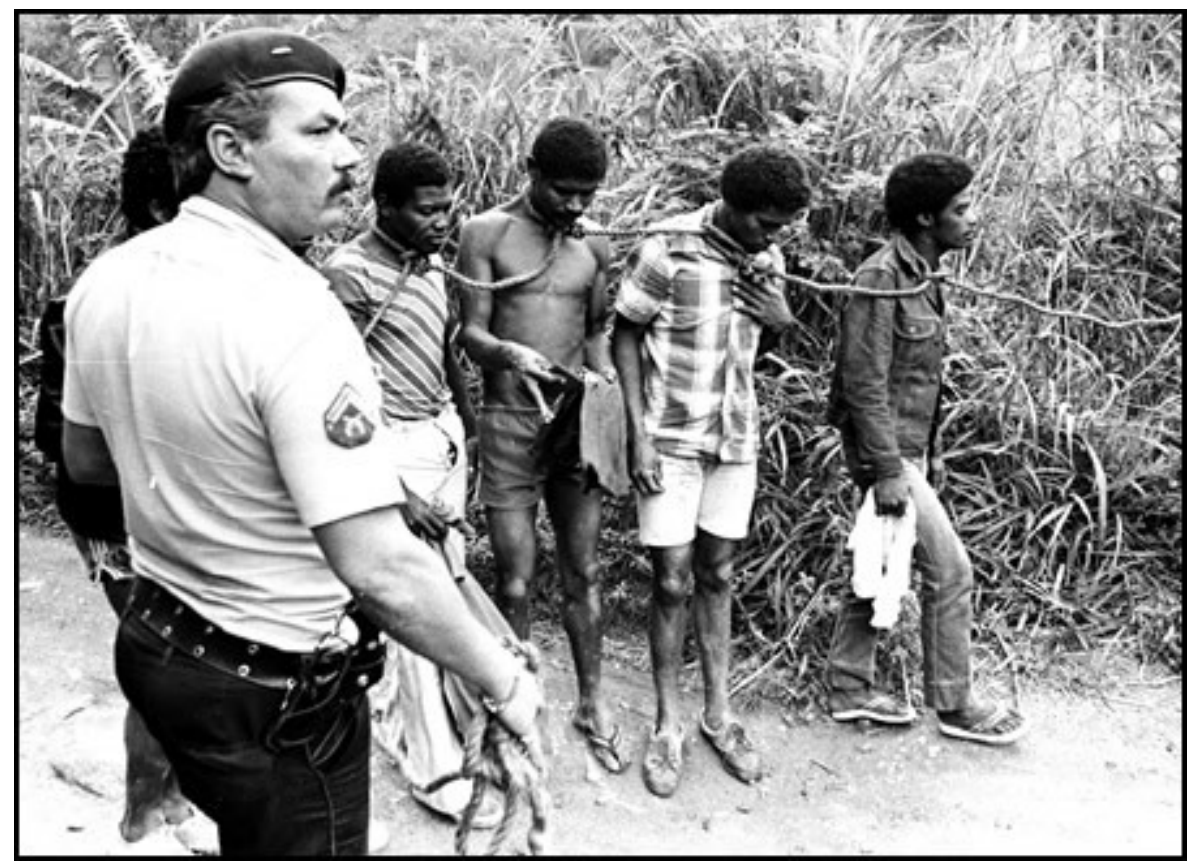

Imagem 1 - A prática do libambo numa fotografia de Luiz Morier intitulada "Todos Negros", vencedora do Prêmio Esso de Fotografia de 1983 e publicada na primeira página do JB de 30 de setembro de 1982. Disponível em: <http://www.abi.org.br/todos-negros/>, acesso em 20 mai. 2020.

Outro aspecto importante no que diz respeito à violência no transporte de africanos escravizados é a condição de acomodação dos mesmos durante a travessia do Atlântico. As condições desumanas a que estavam submetidos, viajando amontoados e acorrentados nos porões e no convés dos navios, recebiam pouquíssimas porções de água e mantimentos. A desnutrição e as doenças de pele e olhos eram disseminadas entre a carga humana dos navios negreiros, ou tumbeiros, levando a uma mortalidade de aproximadamente um décimo dos transportados. As somas arrecadadas no lucrativo comércio cobriam largamente essas perdas (CONRAD, 1985).

Enquanto o tráfico atlântico de africanos escravizados foi lícito, entre meados do século XV e início do século XIX, os governos metropolitanos e autoridades coloniais procuraram regulamentar o transporte e a carga máxima dos navios. Após a proibição do tráfico atlântico e a disseminação do tráfico ilegal de meados do século XIX, essas regulamentações perderam seu valor e os traficantes envolvidos no contrabando passaram a explorar as cargas máximas possíveis, agravando as condições de insalubridade das embarcações e aumentando os índices de perdas, compensados pela elevação dos preços de mercado. Essa situação foi mobilizada pelos defensores da escravidão na política brasileira, que passaram a defender a liberação do tráfico que fora 
Revista do Corpo Discente do Programa de Pós-Graduação em História da UnB

Em TEMPO DE HISTÓRIAS | Brasília-DF | n. 36 | p. 252-272 | jan./jun. 2020.

ISSN 2316-1191

proibido a partir de uma argumentação falsamente humanitária, alegando que o tráfico regulamentado era menos cruel que o contrabando. (CHALHOUB, 2012).

\section{Direitos humanos e interseccionalidade no Oeste catarinense}

Tendo como eixo principal da integração curricular a problematização das relações étnico-raciais no Brasil, é de suma importância compreender os fundamentos filosóficos da criação e afirmação dos direitos humanos na perspectiva da sua gênese bem como de sua aplicação na realidade local. O método escolhido para investigar este tema é o do estudo de caso, que procura investigar como os imigrantes haitianos chegaram a Santa Catarina a partir de 2015, em especial, em Xanxerê. Cabe salientar que “ [...] Santa Catarina tornou-se o estado brasileiro com o maior volume de trabalhadores estrangeiros de nacionalidade haitiana vinculado ao mercado formal de trabalho (CAGED/MTE, 2015). (MAGALHÃES, 2017). Não menos importante, é que Santa Catarina também é o que pior remunera os trabalhadores estrangeiros, segundo Magalhães (2017). Essas são contradições que nos moveram a pesquisar a questão da imigração haitiana, juntamente com os direitos humanos e a questão racial.

A partir do Cadastro Único (CAdÚnico), fornecidos pela Secretaria da Assistência Social do Estado, "Santa Catarina contabilizava até final de 2019, um total de 5.762 imigrantes registrados". (SPAUTZ, 2019). O número certamente deve ser maior, pois muitos imigrantes de diferentes nacionalidades acabam vindo de outros estados e por circunstâncias diversas não se cadastram no órgão estadual. O número de haitianos, segundo os dados obtidos pelo cadastro único, fica em 3.343 em Santa Catarina. Este grupo de imigrantes, em especial, é de importância para nossa integração curricular, pois se trata de um novo grupo afrodescendente a compor o mosaico étnico da sociedade brasileira, produzindo a interseccionalidade entre a temática dos direitos humanos e a questão racial. Isto nos leva a poder relacionar a história do Haiti como tema privilegiado para compreender melhor a nossa própria história e nossa sociedade, desigual, pobre, e com problemas sociais graves e persistentes. Assim sendo, temos alguns questionamentos básicos a fazer, por exemplo, como os direitos humanos foram efetivados no Haiti? Para além disso, os haitianos que chegaram a Xanxerê tiveram durante o trajeto de viagem seus direitos humanos respeitados? Antes de responder a estas questões, precisamos compreender o que entendemos por direitos humanos.

A tese que aqui se coloca é que os direitos humanos são direitos que transcendem os Estados nacionais e são naturais a todos seres humanos indistintamente de sua etnia, gênero, cor, nacionalidade, orientação sexual ou preferência política. Dessa forma, são direitos interseccionais por excelência. Assim foram definidos pela Declaração Universal dos Direitos Humanos da ONU, em 1948. Os direitos humanos devem ser compreendidos como necessidades básicas, sem as quais ninguém pode viver dignamente. Infelizmente, em muitos lugares do mundo o direito - como um sistema de garantias ou regras válidas intersubjetivamente, sendo consideradas legítimas por ambas as partes - ainda é visto como um privilégio de determinados grupos (como ainda comumente acontece em vários lugares). A igualdade jurídica ainda é um ideal não realizado para milhões de pessoas. 
Revista do Corpo Discente do Programa de Pós-Graduação em História da UnB

Em TEMPO DE HISTóRIAS | Brasília-DF | n. 36 | p. 252-272 | jan./jun. 2020.

ISSN 2316-1191

Isso ocorre porque vivemos ainda num mundo com muitas barreiras, fronteiras e muros. Para exemplificar isso, note-se que somente se dá ou tem direitos quem pertence a algum Estado, sendo que ainda estamos sob o signo da Soberania Estatal. E isso parece recrudescer, basta ver como os Estados Unidos e alguns países da Europa, como a Hungria, por exemplo, fecham suas fronteiras e aumentam os discursos nacionalistas. Desta forma, a discussão dos direitos humanos se torna relevante, pois estes não valem para alguém com alguma nacionalidade, mas para todos indiscriminadamente. Foi a partir da sua criação, que o axioma de que todos os seres humanos têm direitos, ou seja, todos têm o "[...] direito a ter direitos, ou o direito de cada indivíduo de pertencer à humanidade" (ARENDT, 1989, p. 332), deveria valer.

Cabe destacar que hoje somente têm direitos os cidadãos que pertence a algum Estado - como alguns críticos já apontaram (Agamben, Zizek) - pois quem garante a sua aplicação e defesa - sejam os direito humanos ou direitos constitucionais nacionais sempre é um Estado, uma Nação. Ainda impera hoje em muitos lugares noções segundo as quais o estrangeiro ou pobre é um cidadão de segunda classe. Por isso a precariedade, ainda hoje, dos estrangeiros, dos pobres e dos imigrantes em qualquer parte do planeta. Exemplos contemporâneos disto são os imigrantes forçados por guerras a saírem de seus Estados, ou mesmo os índios brasileiros (que tem um Estado, mas que este mesmo Estado pouco se preocupa com ele). Temos aqui na América do Sul, os exemplos dos venezuelanos. Outros que migraram para outras partes do mundo são os sírios e haitianos (por razões diversas), e que não são reconhecidos como pessoas que são dignas de serem respeitadas quando estes procuram asilo, refúgio ou mesmo melhores condições para viver em outro país, sofrendo com o racismo e a xenofobia.

A questão é: Por que os direitos humanos não são respeitados? Todos aqueles que se vêem sem um Estado, uma Pátria, que supostamente deveria garantir algum direito, se encontram na condição de "imigrantes". Estes acabam tendo todos ou grande parte dos seus direitos negados, tornando-se refugiados ou pessoas apátridas, ou seja, seres humanos matáveis. Essa figura, foi definida como sendo o Homo sacer, que Giorgio Agamben (2002, p.91), filósofo italiano, descreveu como sendo a condição da vida que impera hoje. O autor mostra que o Homo sacer é aquela pessoa que pode ter sua vida exposta como "matavél e insacrificável", posta à crueza da vida nua, abandonada ao acaso das escolhas dos governantes e dos órgãos de proteção, como a ONU. Segundo Slavoj Zizek, temos uma condição estranha no mundo contemporâneo, pois ele se divide entre o cidadão e o refugiado, ou como ele define, usando o conceito de Agamben, o Homo sacer. Portanto, junto aos exemplos atuais do Homo sacer (os sans papiers na França, os habitantes das favelas no Brasil, a população dos guetos afro-americanos nos EUA etc.) se encontram que aqueles vistos como recipientes da ajuda humanitária (ZIZEK, p.115116).

Vejamos de que forma esta noção de ajuda humanitária a imigrantes se torna relevante para o ensino das relações étnico-raciais no contexto do Oeste catarinense. Houve grande divulgação na mídia brasileira quando, em 2010, três tremores atingiram o Haiti, precisamente na capital, Porto Príncipe, num raio de 22 quilômetros. A Organização das Nações Unidas (ONU) contabilizou 1,5 milhões de desabrigados, 300 mil feridos e cerca de 220 mil mortos, o que significa que um terço da população haitiana 
Revista do Corpo Discente do Programa de Pós-Graduação em História da UnB

EM TEMPO DE HISTóRIAS | Brasília-DF | n. 36 | p. 252-272 | jan./jun. 2020.

ISSN 2316-1191

foi afetada. Grande parte da população de Xanxerê (assim como do Oeste catarinense e do Brasil) acredita que os imigrantes haitianos no Brasil sejam "refugiados" do terremoto. No entanto, nenhum dos 30 estudantes haitianos no curso FIC do Câmpus Xanxerê informou ter sido afetado pelo terremoto. Isso indica que a população imigrante não está relacionada diretamente à catástrofe natural e à crise humanitária derivada dele, sendo composta por uma parcela economicamente remediada da população que viu na abertura das fronteiras do Brasil para os imigrantes haitianos uma oportunidade de melhorar suas vidas através do trabalho.

Os haitianos começaram a vir para o Brasil de forma mais organizada a partir de 2012. A possibilidade foi aberta por estar o Brasil no comando da MINUSTAH, mas alguns deles viam o país como atrativo por conta da possibilidade de oferta de emprego. Os imigrantes levaram principalmente em consideração a facilidade de encontrar um emprego regular, já que no Haiti não havia essa perspectiva, sendo o mercado de trabalho marcado pela sazonalidade. Até 2016, chegaram ao Brasil, 73.077 haitianos. Segundo o Instituto de migrações e direitos humanos, o modo como conseguiram legalizar a sua entrada no Brasil, aconteceu da seguinte forma: 55,08\% com Visto Humanitário emitido pelo Ministério das Relações Exteriores (Embaixadas e Consulados); $40.51 \%$ com base na decisão conjunta do Conselho Nacional de Imigração (CNIg) e do Comitê Nacional para Refugiados (CONARE). Os dados apresentados no gráfico 1 mostram a entrada de haitianos no Brasil durante o período 2012-2016 foi crescente e atingiu um pico em 2016.

\section{Gráfico 1 - Haitianos que se registraram na Polícia Federal}

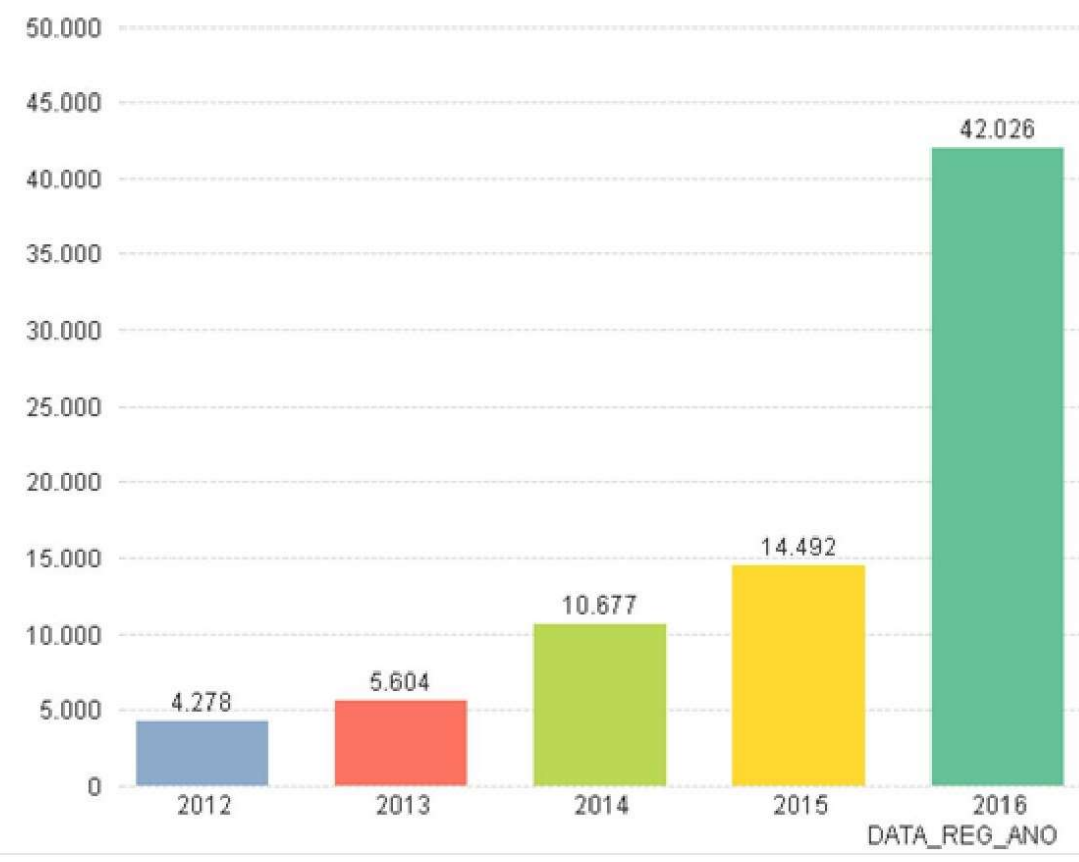

Fonte: Dados fornecidos pela Polícia Federal ao CNIg 
Revista do Corpo Discente do Programa de Pós-Graduação em História da UnB

Em TEMPO DE HISTóRIAS | Brasília-DF | n. 36 | p. 252-272 | jan./jun. 2020.

ISSN 2316-1191

Dados coletados pela Polícia Federal e apresentados pela CNIg, mostram em quais estados da federação os imigrantes haitianos se registraram e quais foram as principais fontes de ocupação laboral que os haitianos conseguiram no Brasil, respectivamente os gráficos 2 e 3 :

\section{Gráfico 2 - Estados da Federação nos quais os haitianos se registraram}
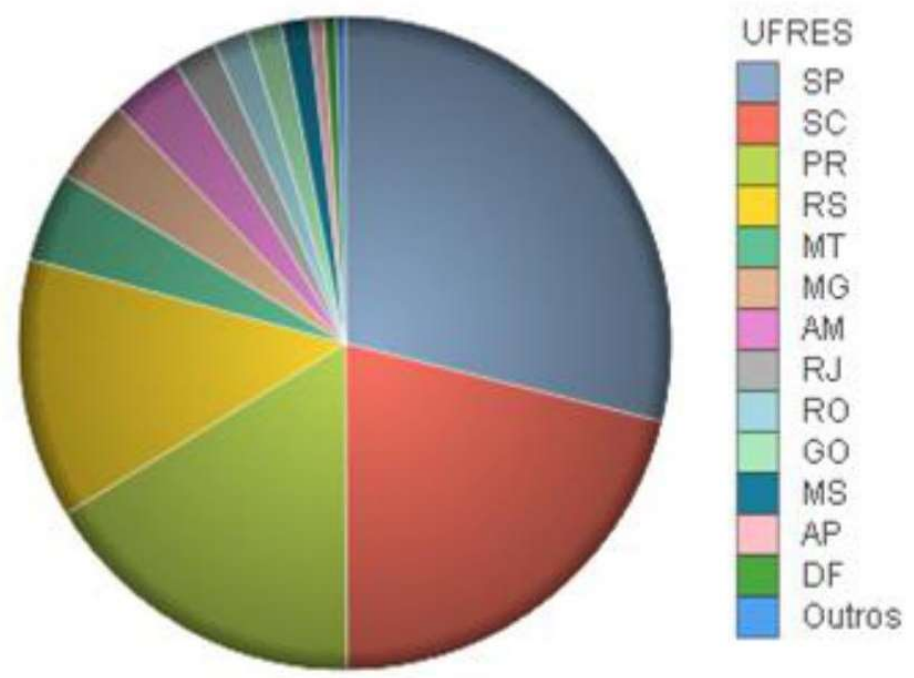

$28,85 \%$

$21,07 \%$

$16,36 \%$

$12,88 \%$

$4,46 \%$

$4,17 \%$

$3,53 \%$

$2,12 \%$

$1,74 \%$

$1,68 \%$

$1,39 \%$

$0,70 \%$

$0,63 \%$

$0,43 \%$

Fonte: Polícia Federal, dados fornecidos ao CNIg.

\section{Gráfico 3 - Ocupação declarada pelos imigrantes haitianos ao se registrarem}

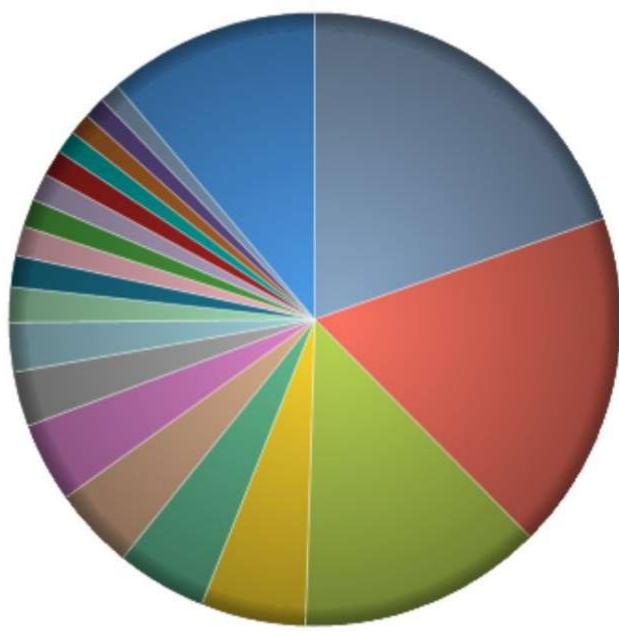

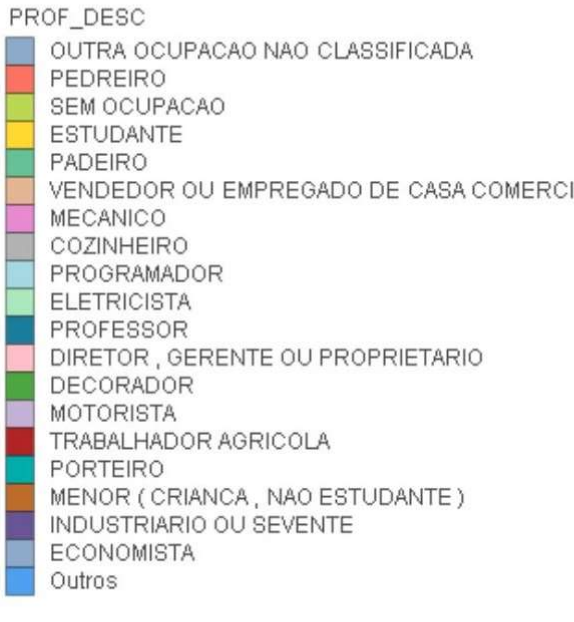

Fonte: Dados fornecidos pela Polícia Federal ao CNIg 
Revista do Corpo Discente do Programa de Pós-Graduação em História da UnB

EM TEMPO DE HISTóRIAS | Brasília-DF | n. 36 | p. 252-272 | jan./jun. 2020.

ISSN 2316-1191

É possível notar que as ocupações em que estão conseguindo se inserir são, em sua maioria, subempregos ou trabalhos que exigem pouca escolaridade. Isso não é percebido como um problema para os haitianos que chegam com baixa escolaridade no país. Eles conseguem empregos em funções equivalentes às que desempenhavam no Haiti, por exemplo, na construção civil, com remuneração equivalente, mas com a diferença de não estarem sujeitos à sazonalidade do trabalho. Já os haitianos que chegam com formação superior no Brasil são os mais insatisfeitos com os trabalhos nos quais conseguem se inserir e aqueles que se consideram desiludidos com as perspectivas profissionais vislumbradas. O estado de Santa Catarina é o segundo mais procurado por haitianos para viver e trabalhar, fato que os mesmos atribuem à maior disponibilidade de empregos. Segundo reportagem de Aline Takashima, publicada no jornal Maruim, de Florianópolis, esta observa:

Oriundos de um país com uma população formada por 95\% de negros, de acordo com The World Factbook (banco de dados da Comunidade de Inteligência dos Estados Unidos, a CIA), milhares de haitianos têm chegado no estado [Santa Catarina] que tem a maior proporção de brancos (85\%) e a menor de negros no Brasil (15\%), conforme o censo de 2014 do IBGE. Neste cenário, os relatos de episódios de racismo não são raros (TAKASHIMA, 2017).

Alguns dados do contexto regional do Oeste catarinense podem ilustrar melhor essa situação. Estudantes do curso FIC oferecido para haitianos no Câmpus Xanxerê do IFSC, relataram que é comum que homens brancos da região abordem e ofereçam dinheiro para as haitianas nas ruas da cidade, mesmo para as casadas e acompanhadas, demonstrando uma mentalidade que associa as imigrantes negras à prostituição e à miséria. Outros afirmam que sofrem com piadas e brincadeiras de mau gosto no trabalho pelo desconhecimento da língua portuguesa. Também são relatados casos de pessoas oferecendo roupas velhas e usadas a haitianos que não estão pedindo por isso, como se todos fossem naturalmente pobres e necessitados. É expressivo do racismo que numa região de descendentes de imigrantes europeus, somente os imigrantes negros sejam vistos como miseráveis. Há uma forte influência da história das relações étnico-raciais do país e da mídia atual na construção dessas visões sobre os haitianos. A objetificação do corpo negro feminino que teve origem na violência sexual que caracterizou a sociedade escravista é reforçada em momentos como os desfiles de escolas de samba no Carnaval. Por outro lado, o Haiti é sempre mostrado na mídia como um país miserável, como se não houvesse belezas humanas e naturais, riqueza cultural, elites abastadas em função da concentração de renda.

Visando desconstruir esses estereótipos e desenvolver uma educação antirracista e antixenófoba, os professores do curso FIC "Língua Portuguesa e Cultura Brasileira para estrangeiros" desenvolveram junto com os estudantes haitianos o projeto "O Haiti não é aqui / O Haiti é aqui". Foram assim selecionadas pelos estudantes imagens que representavam as riquezas naturais, culturais, culinárias e paisagísticas de seu país. Em contraste, foram pesquisadas imagens que retratavam a pobreza e a miséria no Brasil. Assim, foi organizada uma exposição no câmpus que permitiu aos estudantes brasileiros conhecerem outra face do Haiti não apresentada na mídia nacional. Interessante notar que muitos estudantes haitianos, que conheciam apenas a realidade dos centros urbanos em que estavam inseridos, se chocaram ao saber que existiam 
Revista do Corpo Discente do Programa de Pós-Graduação em História da UnB

Em TEMPO DE HISTóRIAS | Brasília-DF | n. 36 | p. 252-272 | jan./jun. 2020.

ISSN 2316-1191

brasileiros que viviam em condições de miséria como as populações das palafitas de Santos, Recife e Rio de Janeiro, as populações ribeirinhas do Norte do país, ou mesmo em aldeias indígenas do Oeste catarinense.

A partir dessas considerações, chegamos ao estudo de caso, propriamente dito. Intencionalmente escolhemos entrevistar uma mulher imigrante haitiana egressa do curso FIC oferecido no câmpus, que segundo ela mesma, resolveu buscar melhores condições de vida e trabalho no Brasil. A entrevista foi conduzida pelo professor de Filosofia junto a uma estudante bolsista e o depoimento da haitiana integrou o material didático produzido para estudo multidisciplinar. Por motivos éticos, o nome usado será um nome fictício para preservar a sua imagem. "Marta" é uma imigrante haitiana que está no Brasil há cinco meses. Ela nos conta que veio para o Brasil em busca de trabalho, já que em seu país a situação de desemprego é altíssima. Ela tem um curso de graduação, mas não conseguia emprego lá, algo muito comum no Haiti, segundo relata.

Foi perguntado a Marta se ela tinha sido afetada pelo terremoto, e se a situação de desemprego tem relação com a tragédia. Marta diz que não foi afetada diretamente pelo sismo, e que há anos o país sofre com uma alta taxa de desemprego. Segundo relato da imigrante, uma pequena parcela da sociedade haitiana foi afetada pela tragédia, e que as pessoas que decidem sair do país são aqueles e aquelas que há um certo tempo vêm guardando fundos para imigrar para outros países em busca de trabalho regular e de uma vida melhor. No Brasil, a pior coisa que aconteceu a ela, afirma, foi o racismo. Foi justamente numa missa, na hora de dar as mãos - numa parte da liturgia católica uma pessoa ao seu lado se negou a dar a mão para ela, por ser uma pessoa negra. "Isso dói”, afirma, mas, para Marta, essa foi a única coisa ruim que ela encontrou no Brasil. Quanto ao fato de ter algum dos direitos humanos desrespeitados durante a viagem, na sua concepção - afirma Marta - não sofreu. Com exceção do racismo no Brasil.

\section{Considerações finais}

Além de viabilizar a elaboração de um material multidisciplinar no qual os resultados da pesquisa foram organizados em forma didática para o ensino em Ciências Humanas, a experiência de trabalho docente integrado a partir dos temas das relações étnico-raciais e dos direitos humanos foi rica em muitos sentidos. Podemos dizer que contribuiu para nossa formação continuada enquanto educadores, para a iniciação científica das estudantes bolsistas e para uma educação antirracista com as turmas de Ensino Médio, assim como para a abertura de novas perspectivas de trabalho pedagógico com os estudantes haitianos no câmpus.

A pesquisa sobre os haitianos em busca de uma vida melhor no Brasil indica que os direitos humanos não teriam sido desrespeitados, na perspectiva dos próprios imigrantes. Entretanto, o ato racista que Marta sofreu na igreja, assim como os relatos de propostas para programas sexuais e de brincadeiras de mau gosto no trabalho feitos por outros, indicam que há um racismo estrutural no Oeste catarinense, que se associa a manifestações machistas e xenófobas. A não percepção dessas situações como violações a direitos pode residir no desconhecimento acerca dos mesmos direitos. Embora a legislação sobre direitos humanos seja internacional, estes não são muito divulgados ou 
Revista do Corpo Discente do Programa de Pós-Graduação em História da UnB

EM TEMPO DE HISTóRIAS | Brasília-DF | n. 36 | p. 252-272 | jan./jun. 2020.

ISSN 2316-1191

efetivados no Haiti. Por outro lado, não há por parte das autoridades brasileiras um esforço no sentido de conscientizar os imigrantes a respeito de seus direitos trabalhistas.

É significativo que a formação em direitos trabalhistas foi uma demanda dos estudantes haitianos para o curso FIC, pois os mesmos se sentiam desprotegidos por causa do desconhecimento legal. Aproveitamos então esta oportunidade para oferecer também uma formação acerca dos direitos humanos. Tendo deixado o Haiti em busca de melhores condições de trabalho, foi nos ambientes de trabalho que os haitianos se perceberam desamparados juridicamente. Isso parece estar relacionado mais à frustração de suas expectativas. Por outro lado, os brasileiros tendem a olhar para os haitianos como pobres e vítimas do terremoto de 2010, senso comum reforçado pela mídia, como sobreviventes de uma catástrofe natural e necessitados de ajuda humanitária. Esta situação os coloca numa condição de Homo sacer. São focadas as atenções nas barbáries que eles supostamente passaram no Haiti e omitidas aquelas pelas quais eles efetivamente passam no Brasil.

Brasil e Haiti comungam um passado de escravismo e marcado pela diáspora africana. Isto faz com que a educação das relações étnico-raciais seja relevante para a desconstrução de preconceitos em ambos os países, valorizando-se a história e a contribuição da cultura dos povos africanos para as Américas. Além disso, os negros foram durante muito tempo destituídos de sua condição humana pelas relações escravistas de trabalho e pelo tráfico atlântico, sendo equiparados a ferramentas ou animais. Isso indica uma interseção entre a educação das relações étnico-raciais e a educação em direitos humanos com grande potencial a ser explorado. Valorizar a história do Haiti e apresentar a riqueza de sua cultura é combater o racismo e as violações de direitos dos negros no Brasil. De forma análoga, uma educação antirracista que valorize a cultura afro-brasileira e que repudie as barbáries cometidas na época da escravidão e do tráfico atlântico de africanos escravizados contribui para o respeito aos imigrantes haitianos no Brasil contemporâneo. Uma educação das relações étnicoraciais e dos direitos humanos, a partir de uma perspectiva interseccional, oferece ainda a possibilidade de integrar os currículos escolares e oferecer uma formação crítica, cidadã e emancipatória, trabalhando com temas transversais.

Assim, acreditamos que falar de racismo e de direitos humanos é essencial, porque é falar de barbárie e atrocidades. Esse conceito abstrato, de "direitos humanos ou dignidade" é ainda ignorado ou deturpado em muitas partes do mundo. No Brasil, vemos uma face dessa tendência expressa na absurda fórmula "direitos humanos para humanos direitos". Ainda que falar em dignidade possa muitas vezes parecer algo obscuro, é somente através desta ideia que os Direitos Humanos podem ser construídos e implementados na realidade social. A dignidade ou os Direitos Humanos são uma necessidade básica, sem a qual não se pode desenvolver minimamente uma existência salvaguardada da miséria, da fome e das diversas formas de violência.

\section{Referências}

AGAMBEN, Giorgio. Homo Sacer: o poder soberano e a vida nua I. Belo Horizonte: Editora UFMG, 2002. 
Revista do Corpo Discente do Programa de Pós-Graduação em História da UnB

EM TEMPO DE HISTóRIAS | Brasília-DF | n. 36 | p. 252-272 | jan./jun. 2020.

ISSN 2316-1191

ARENDT, Hannah. Origens do Totalitarismo: antissemitismo, imperialismo, totalitarismo. São Paulo: Companhia das Letras, 1989.

ALMEIDA, Maria Regina Celestino de. Os índios na História do Brasil. Rio de Janeiro: Editora FGV, 2010.

ARAPYUM, Iára Ferreira; CRUZ, Cauã Nóbrega da. Para fazer de nossa sociedade um lugar livre de preconceito contra os povos indígenas. Santarém: Ministério Público Federal no Pará, 2017.

ASSIS, Dayane N. Conceição de. Interseccionalidades. Salvador: UFBA, Instituto de Humanidades, Artes e Ciências; Superintendência de Educação a Distância, 2019.

BITTENCOURT, Circe. "Identidade nacional e o ensino de História do Brasil". In KARNAL, Leandro (org.). História na sala de aula: conceitos, práticas e propostas. 5 ed. São Paulo: Contexto, 2007.

CHALHOUB, Sidney. A força da escravidão: ilegalidade e costume no Brasil oitocentista. São Paulo: Companhia das Letras, 2012.

CONRAD, Robert. Tumbeiros: o tráfico de escravos para o Brasil. São Paulo: Brasiliense, 1985

CUNHA, Manuela Carneiro da. Índios no Brasil: história, direitos e cidadania. São Paulo: Claro Enigma, 2012.

DEMO, Pedro. Pesquisa: princípio científico e educativo. $12^{\mathrm{a}}$ ed. São Paulo: Cortez, 2006.

LEWKOWICZ, Ida; GUTIÉRREZ, Horacio; FLORENTINO, Manolo. Trabalho compulsório e trabalho livre na história do Brasil. São Paulo: Editora UNESP, 2008.

LOVEJOY, Paul E. A escravidão na África: uma história de suas transformações. Rio de Janeiro: Civilização Brasileira, 2002.

MAGALHÃES, Luís Felipe Aires. A imigração haitiana em Santa Catarina: perfil sociodemográfico do fluxo, contradições da inserção laboral e dependência de remessas no Haiti. 2017. 355 f. Tese (Doutorado em Demografia) - Programa de Pós-Graduação em Demografia, Universidade Estadual de Campinas, Campinas, 2017.

MARQUESE, Rafael; SALLES, Ricardo (org.). Escravidão e capitalismo histórico no século XIX: Cuba, Brasil e Estados Unidos. Rio de Janeiro: Civilização Brasileira, 2016.

PARANÁ (Presidência da Província do). Relatório do presidente da província do Paraná, o conselheiro Zacarias de Góes e Vasconcellos, na abertura da Assembleia Legislativa Provincial em 15 de julho de 1854. Curitiba: Typ. Paranaense de Candido Martins Lopes, 1854.

SANTOS, Joel Rufino dos. O que é Racismo. 8 ed. São Paulo: Brasiliense, 1984.

SCHWARCZ, Lilia Moritz. "Espetáculo da miscigenação". Estudos Avançados, São Paulo, v. 8, n. 20, p. 137-152, abr. 1994.

SILVA, Adriano Larentes da. Currículo Integrado. Florianópolis: IFSC, 2014.

SPAUTZ, Dagmara. (Santa Catarina). "Santa Catarina tem 5,7 mil imigrantes no cadastro de programas sociais". NSC Total. 2019. Disponível em: 
Revista do Corpo Discente do Programa de Pós-Graduação em História da UnB

Em TEMPO DE HISTóRIAS | Brasília-DF | n. 36 | p. 252-272 | jan./jun. 2020.

ISSN 2316-1191

<https:/www.nsctotal.com.br/colunistas/dagmara-spautz/santa-catarina-tem-57-milimigrantes-no-cadastro-de-programas-sociais>. Acesso em: 20 maio 2020.

TAKASHIMA, Aline. (Florianópolis). "A vida dos haitianos em Santa Catarina". Maruim Jornalismo, 30 jan. 2017. Disponível em: <http://maruim.org/2017/01/30/especial-travessia-a-vida-dos-haitianos-em-santacatarina/>. Acesso em: 19 mai. 2020.

ZIZEK, Slavoj. Bem vindo ao deserto do real!: Cinco ensaios sobre o 11 de setembro e datas relacionadas. São Paulo: Boitempo, 2003. 